\title{
Single month Labour Force Survey estimates: November 2011 (Not designated as National Statistics)
}

\author{
Author Name(s): Sonia Simpkins, Office for National Statistics
}

\begin{abstract}
This report contains charts that compare the Labour Force Survey (LFS) headline three-month average rates for employment, unemployment and economic inactivity with their equivalent single month estimates. The single month estimates are derived from the same data source as the headline three-month figures but are not designated as National Statistics and their use is restricted to helping to understand the movements in the headline three-month averages.
\end{abstract}

\section{Labour Force Survey single month estimates}

This report contains charts that compare the Labour Force Survey (LFS) headline three-month average rates for employment, unemployment and economic inactivity with their equivalent single month estimates. The single month estimates are derived from the same data source as the headline three-month figures but are not designated as National Statistics and their use is restricted to helping to understand the movements in the headline three-month averages.

Key points to note are as follows:

- The LFS single month estimates provide additional information about the latest quarterly movements in the headline three-monthly aggregates of employment, unemployment and economic inactivity.

- The production and evaluation of the estimates is an important part of the ONS' quality assurance of the three-monthly averages published in the Labour Market Statistical Bulletin.

- The estimates help users determine the extent to which the movements in the headline aggregates are true reflections of changes in the UK labour market and the extent to which they reflect the survey nature of the LFS, in particular sampling variability.

- The sampling variability of the single month estimates is higher in relative terms than that of the headline aggregates and so any interpretation of them can only be in fairly broad terms.

- The movement in the latest single month figures is, in theory, a better indication of the latest change in the labour market than the difference between the latest two overlapping three-month periods, but it must still be treated with caution. 
- The sample design of the LFS often produces clear patterns in the single month series which can aid interpretation of the LFS aggregates.

- The single month estimates are regarded as an "official statistic" and are not considered National Statistics in their own right because they do not have sufficient methodological robustness.

- Improvements to the methodology for producing the single month estimates have been identified and work is ongoing to implement them in the future.

For the three month averages, the dates shown on the charts relate to the last month of the three (e.g. January - March is indicated by March).

\section{Methodological article}

A methodological article explaining the background to the LFS single month estimates and describing how they are calculated is available.

\section{UK employment rates 16-64 (seasonally adjusted)}

The single month estimate for September 2011 shows a decrease of 0.2 percentage points on the previous month.

\section{UK employment rates 16-64 (seasonally adjusted)}

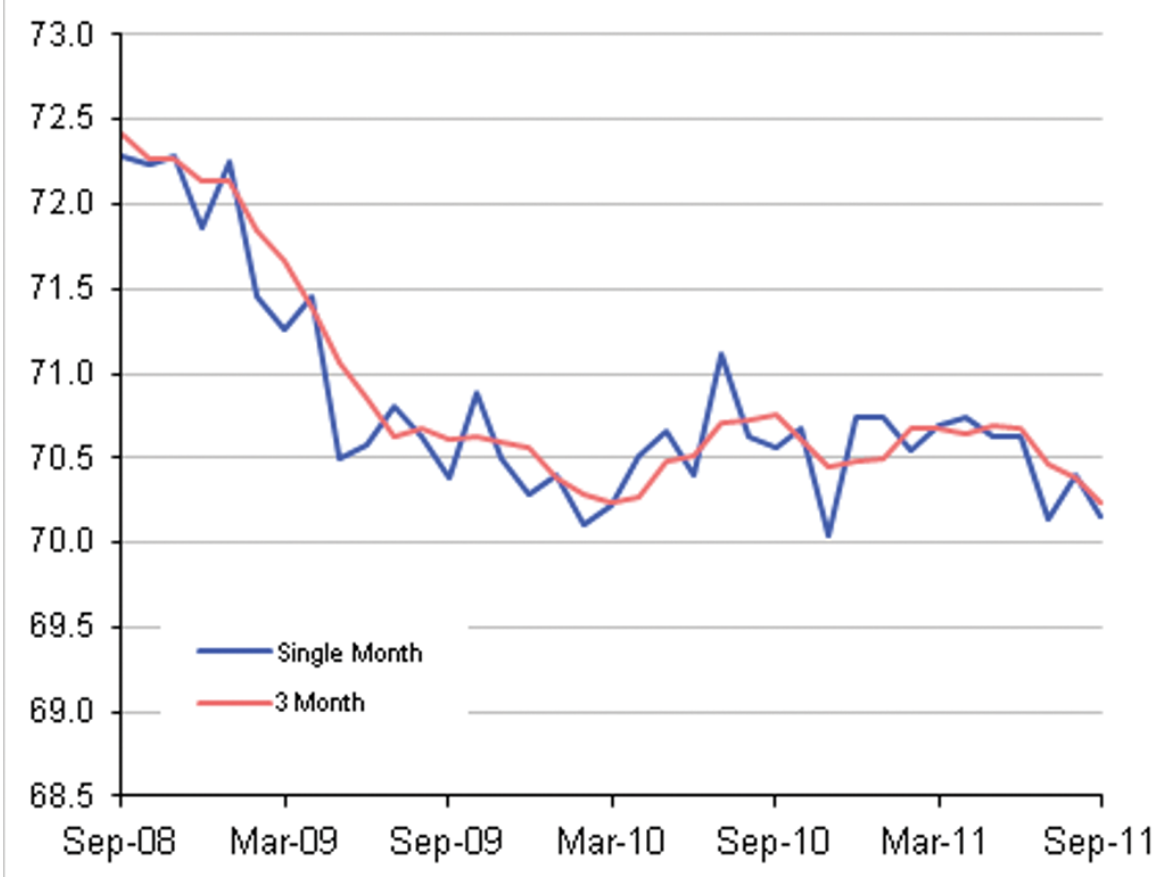

Source: Labour Force Survey - Office for National Statistics 


\section{Download chart}

XLS XLS format

$(116 \mathrm{~Kb})$

\section{UK unemployment rates $16+$ (seasonally adjusted)}

The single month estimate for September 2011 shows an increase of 0.2 percentage points on the previous month.

UK unemployment rates $16+$ (seasonally adjusted)

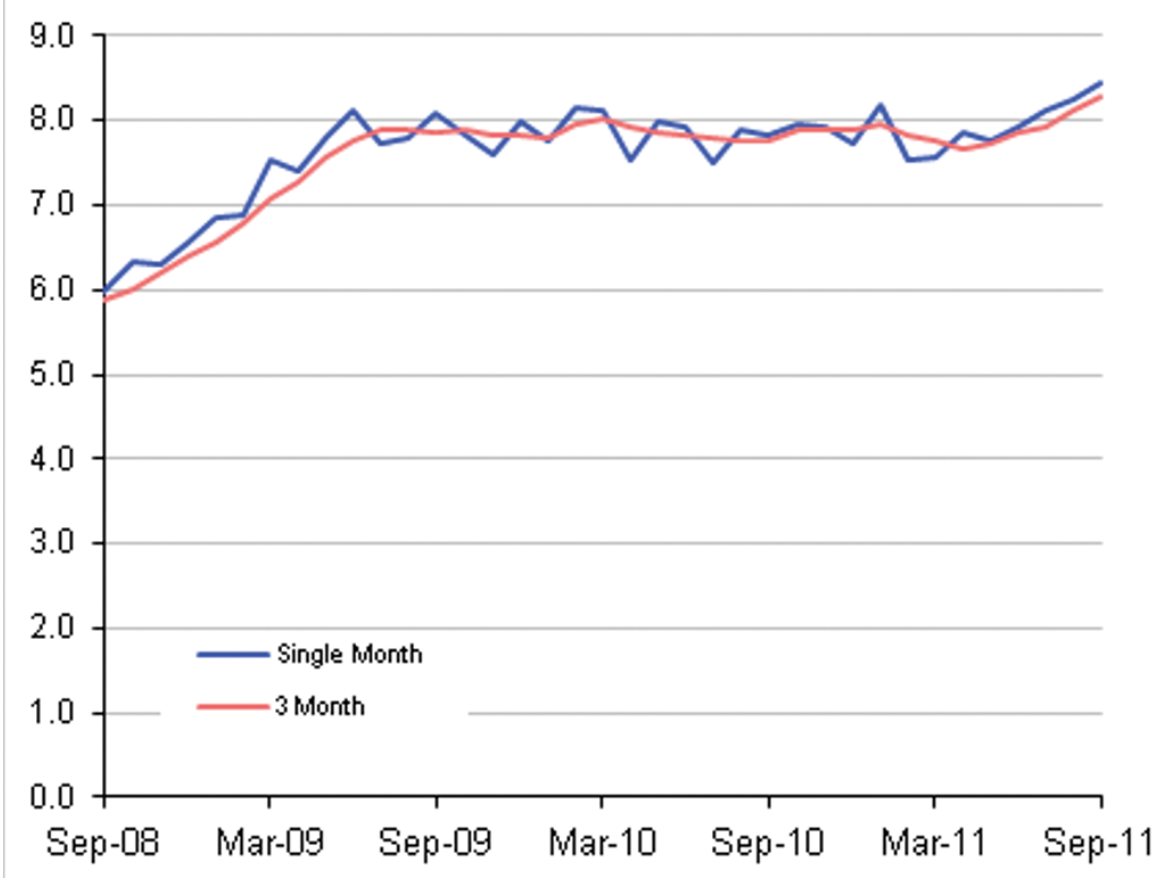

Source: Labour Force Survey - Office for National Statistics

\section{Download chart}

XLS XLS format

$(116 \mathrm{~Kb})$

\section{UK economic inactivity rates $16-64$ (seasonally adjusted)}

The single month estimate for September 2011 shows an increase of 0.1 percentage points on the previous month. 
UK economic inactivity rates 16-64 (seasonally adjusted)

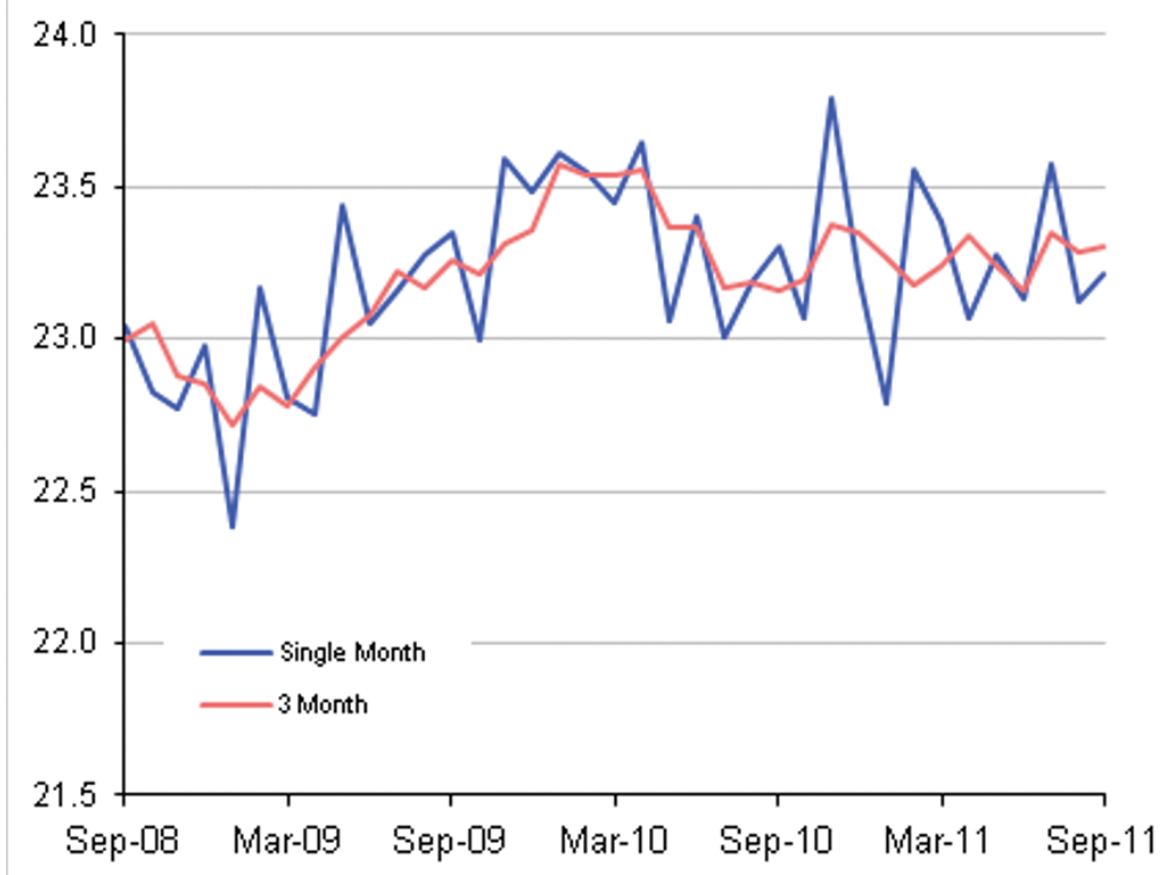

Source: Labour Force Survey - Office for National Statistics

\section{Download chart}

XLS XLS format

$(116 \mathrm{~Kb})$ 